\title{
Methanol-to-olefin conversion over H-MCM-22 catalyst
}

\author{
Lei Zhang ${ }^{\mathrm{a}, \mathrm{b}}$, Hui Wang ${ }^{\mathrm{a}, *}$, Guangbo Liu ${ }^{\mathrm{a}}$, Kun Gao ${ }^{\mathrm{a}}$, Jinhu $\mathrm{Wu}^{\mathrm{a}, *}$ \\ a Key Laboratory of Biofuels, Qingdao Institute of Bioenergy and Bioprocess Technology, Chinese Academy of Sciences, Qingdao 266101, PR China \\ ${ }^{\mathrm{b}}$ University of Chinese Academy of Sciences, Beijing 100049, PR China
}

\section{A R T I C L E I N F O}

\section{Article history:}

Received 25 September 2015

Received in revised form

11 November 2015

Accepted 12 November 2015

Available online 17 November 2015

\section{Keywords:}

Methanol

Olefin

H-MCM-22

Catalyst

\begin{abstract}
A B S T R A C T
H-MCM-22 zeolites with different Si/Al ratios were hydrothermally synthesized, also the parent sample was dealuminated by ammonium hexafluorosilicate (AHFS). Then all of the samples were characterized and evaluated for the methanol-to-olefin (MTO) conversion. The correlation of structural and acidic properties of H-MCM-22 with catalytic performance was investigated. The H-MCM-22 ( $\mathrm{Si} / \mathrm{Al}=35.1$ ) exhibits best catalytic stability in all the samples because of its suitable acid site amount and distribution. As for the H-MCM-22 ( $\mathrm{Si} / \mathrm{Al}=35.1)$ after dealumination by AHFS, most of the extra-framework Al species were selectively removed, the selectivity of light olefin was enhanced further and the coke deposition seems to be inhibited.
\end{abstract}

(c) 2015 Elsevier B.V. All rights reserved.

\section{Introduction}

Light olefins, such as ethylene, propylene and butylene, are very important raw materials for the production of polyolefins in modern chemical industry. At present, light olefins are mainly manufactured by thermal cracking of naphtha, which requires high energy consumption with low yield of light olefins. Furthermore, in view of the depletion of world oil reserves, it is urgent to develop new routes to produce light olefins using non-oil feedstocks [1]. During the past decades, methanol-to-olefin (MTO) conversion, as an alternative route for the production of light olefins, has attracted much attention, because methanol can be conveniently manufactured from any carbon-containing resources such as coal, natural gas and biomass [2-5]. In the process of MTO, the dual-cycle mechanism was widely accepted, the initial step is the formation of dimethyl ether (DME) through dehydration of methanol, and then reacts to produce light olefins. Meanwhile, light olefins could further react to paraffins, aromatics via hydrogen transfer reaction [1].

A lot of acidic zeolites and zeotype materials have been used in the MTO reaction since its discovery. The catalytic performances, such as activity, selectivity and stability, are largely dependent on the structure and acidity of catalyst, reaction conditions, etc. Zeolite ZSM-5 and SAPO-34 molecular sieve are two valuable

\footnotetext{
* Corresponding author. Fax: +86532 80662761.

E-mail addresses: huiwangsun@gmail.com (H. Wang),wujh@qibebt.ac.cn (J. Wu).
}

catalysts for the MTO conversion. H-SAPO-34 molecular sieve is highly selective in formation of light olefins due to its moderate acidity and small pore entrances, which has been commercially applied in MTO process [6]. Unfortunately, the catalytic life of SAPO-34 is short due to rapid coke deposition on its surfaces [7], thus, it needs to be frequently regenerated to recover the activity $[8,9]$. H-ZSM-5, with strong acidity and medium channel dimensions, is more resistant to deactivation than H-SAPO-34 and used in MTP process, developed by Lurgi, but its one-pass selectivity to propylene and propylene/ethylene $(\mathrm{P} / \mathrm{E})$ ratio are still needed to improve [10-12]. Moreover, with the increasing gap between the global supply and demand of propylene [13], selective production of propylene from methanol draws more and more attention. Thus, it is necessary to explore new catalyst selectively converting methanol with high propylene yield and $\mathrm{P} / \mathrm{E}$ ratio.

MCM-22 zeolite possesses three independent pore systems, the first one is formed by large cylindrical supercages $(7.1 \AA \times 7.1 \AA \times 18.2 \AA$ ) between layers, the second one is formed by sinusoidal $10 \mathrm{MR}$ channels $(4.1 \times 5.1 \AA)$ and the last one is located at the external surface, covered with 12 MR pockets $(7.1 \AA \times 7.1 \AA \times 7 \AA)[14,15]$. Due to the peculiar pore structure, MCM-22 zeolite has been applied in many catalytic processes and is considered to be a potential catalyst in MTO reaction. Min et al. investigated the role of each pore system of H-MCM-22 in MTO reaction and pointed out that acid sites located in the external 12-ring pockets were detrimental to the MTO selectivity and stability. However, the MTO catalysis in both of the sinusoidal 10-MR channels and the cage-based pore system are selective to propylene formation, therefore high selectivity to propylene 
Table 1

Physical properties of different H-MCM-22 catalysts.

\begin{tabular}{llllll}
\hline Sample & Si/Al & S & BET $\left(\mathrm{m}^{2} \mathrm{~g}^{-1}\right)$ & \multicolumn{2}{l}{ Pore volume $\left(\mathrm{cm}^{3} \mathrm{~g}^{-} \mathrm{Al}^{\mathrm{F}} / \mathrm{Al}^{\mathrm{EF}}\right.$} \\
\cline { 3 - 5 } & & & $V_{\text {micro }}$ & $V_{\text {meso }}$ & \\
\hline H-MCM-22(10.8) & 10.8 & 573 & 0.19 & 0.36 & $84 / 22$ \\
H-MCM-22(28.3) & 28.3 & 597 & 0.20 & 0.49 & $87 / 15$ \\
H-MCM-22 (35.1) & 35.1 & 590 & 0.20 & 0.34 & $85 / 4$ \\
H-MCM-22(49.8) & 49.8 & 350 & 0.11 & 0.40 & $55 / 9$ \\
H-MCM-22 (35.1D) & 96.0 & 553 & 0.20 & 0.24 & $426 / 6$ \\
\hline
\end{tabular}

could be obtained [16]. Wang et al. used phosphorus modified H-MCM-22 for the MTH reaction and found about $40 \%$ selectivity to propylene could be achieved at $100 \%$ methanol conversion over H-MCM-22 loading with $3 \%$ phosphorus [17]. Wang et al. [8] studied the catalytic properties of H-MCM-22 zeolites in the conversion of methanol to hydrocarbons (MTH). They found that the catalytic performance of H-MCM-22 zeolites was greatly affected by the external surface acid sites and the catalytic stability can be enhanced by selectively removing these acid sites with dealumination. Lacarriere et al. suggested that during MTH reaction over H-MCM-22 zeolite, acid sites located inside the supercages are quickly deactivated, and the acid sites located on the external surface and within the sinusoidal micropores are mainly responsible for the MTH reaction [18]. Hence, it was expected that H-MCM-22 may perform well on MTO reaction with high selectivity to propylene.

In this work, $\mathrm{H}-\mathrm{MCM}-22$ with a $\mathrm{Si} / \mathrm{Al}$ ratio ranging from 10.8 to 49.8 was hydrothermally synthesized, and the parent sample was also dealuminated by ammonium hexafluorosilicate (AHFS), then they were characterized and tested in the MTO reaction. The correlation of structural and acidic properties of H-MCM-22 with catalyst stability and product selectivity was investigated.

\section{Experimental}

\subsection{Preparation of catalyst}

MCM-22 samples with various Si/Al ratios were hydrothermally synthesized with silica (Cab-O-Sil M5, Cabot Bluestar Co., Ltd.), sodium aluminate (Sinopharm Chemical Reagent Co., Ltd.), hexamethyleneimine (HMI, 98 wt\%, Jiangsu Fengyuan Bioengineering Co., Ltd.), $\mathrm{NaOH}$ (96 wt\%, Sinopharm Chemical Reagent Co., Ltd.) and distilled water according to the procedures in Ref. [19]. The synthetic gel was prepared with the molar composition of $0.3 \mathrm{NaOH}: \mathrm{SiO}_{2}: x$ $\mathrm{Al}_{2} \mathrm{O}_{3}: 0.5 \mathrm{HMI}: 40 \mathrm{H}_{2} \mathrm{O}$, where $x=0.0333,0.016,0.0125$ and 0.01 . The resulting gel was dynamically crystallized in a Teflon-lined stainless-steel autoclave with a rotation speed of $60 \mathrm{rpm}$ at $150{ }^{\circ} \mathrm{C}$ for 7 days. Then the solid product was washed with distilled water, dried at $110^{\circ} \mathrm{C}$ overnight and calcined at $550^{\circ} \mathrm{C}$ for $8 \mathrm{~h}$. The NaMCM-22 was converted to H-MCM-22 by refluxing twice with $1 \mathrm{M}$ $\mathrm{NH}_{4} \mathrm{NO}_{3}$ solution at $80^{\circ} \mathrm{C}$ for $3 \mathrm{~h}$, followed by drying at $110^{\circ} \mathrm{C}$ overnight and calcination at $550^{\circ} \mathrm{C}$ for $4 \mathrm{~h}$. The obtained $\mathrm{H}-\mathrm{MCM}-22$ zeolites with different $\mathrm{Si} / \mathrm{Al}$ ratios were designated as H-MCM$22(x)$, the actual value of $\mathrm{Si} / \mathrm{Al}$ ratio $x$ of H-MCM-22(x) zeolites was determined by inductively coupled plasma-atomic emission spectrometry (ICP-AES), as shown in Table 1.

The obtained H-MCM-22 (35.1) sample was treated with $0.1 \mathrm{M}$ AHFS solution at $60^{\circ} \mathrm{C}$ for $4 \mathrm{~h}$ under reflux conditions. Then it was filtered, washed with distilled water, dried at $110^{\circ} \mathrm{C}$ overnight and calcined at $550{ }^{\circ} \mathrm{C}$ for $4 \mathrm{~h}$. The sample after dealumination was named as H-MCM-22 (35.1D).

\subsection{Catalyst characterization}

Powder X-ray diffraction (XRD) analysis was carried out by using Bruker D8 Advance X-ray diffractometer with $\mathrm{Cu} \mathrm{K \alpha}$ radiation $(\lambda=1.5418 \AA)$ and operated at $30 \mathrm{kV}$ and $30 \mathrm{~mA}$. Data were recorded in the range of $2 \theta=5-50^{\circ}$ with a step size of $0.02^{\circ}$.

The textural analyses were obtained by nitrogen adsorption/desorption method at $-196^{\circ} \mathrm{C}$ with a Micromeritics ASAP2010 automatic analyzer. Before nitrogen adsorption, the samples were evacuated at $300^{\circ} \mathrm{C}$ for $3 \mathrm{~h}$ in vacuum. The specific surface area was assessed by the Brunauer-Emmett-Teller (BET) method. The micropore volume and the micropore surface area were obtained from the $t$-plot method. The total pore volumes were based on the adsorbed amount at $P / P_{0}=0.99$.

The sample acidity was measured by temperature programmed desorption of ammonia ( $\mathrm{NH}_{3}-\mathrm{TPD}$ ) on a Micromeritics Autochem II Chemisorption Analyzer. Sample of ca. $0.1 \mathrm{~g}$ was pretreated at $550{ }^{\circ} \mathrm{C}$ in $\mathrm{Ar}$ flow $(30 \mathrm{ml})$ for $1 \mathrm{~h}$ and then cooled down to $100^{\circ} \mathrm{C}$ After saturation with $5 \% \mathrm{NH}_{3} / \mathrm{Ar}$, the sample was purged with $\mathrm{Ar}$ flow $\left(30 \mathrm{ml} / \mathrm{min}\right.$ ) at $100^{\circ} \mathrm{C}$ for $2 \mathrm{~h}$ to remove the physically absorbed ammonia. The $\mathrm{NH}_{3}$-TPD profile was obtained from 100 to $600^{\circ} \mathrm{C}$ with a ramping rate of $10^{\circ} \mathrm{C} / \mathrm{min}$.

The acidic properties of the samples were determined by Fourier transform infrared (FT-IR) spectra of adsorbed pyridine on a Nicolet 6700 FT-IR spectrometer. Prior to the measurement, the selfsupporting wafers of the zeolite samples were pretreated under $10^{-2} \mathrm{~Pa}$ at $450^{\circ} \mathrm{C}$ for $2 \mathrm{~h}$ and then cooled down to room temperature, the IR spectra were recorded. After adsorption with pyridine vapor for $1 \mathrm{~h}$ at room temperature and evacuation at $150^{\circ} \mathrm{C}$ for $1 \mathrm{~h}$, the Py-IR spectra were recorded. The Brønsted and Lewis acidities were calculated with the integrated areas of peaks at 1545 and $1450 \mathrm{~cm}^{-1}$ by following the procedures reported in Refs. [20,21].

Al MAS NMR spectra were recorded on a $600 \mathrm{MHz}$ Bruker Avance III equipped with a $4 \mathrm{~mm}$ MAS probe at a spinning rate of $13 \mathrm{KHz}$. The ${ }^{27} \mathrm{Al}$ chemical shift is referred to $\mathrm{Al}\left(\mathrm{NO}_{3}\right)_{3}$ solution.

\subsection{Catalytic tests}

The MTO reaction was carried out under atmosphere pressure in a fixed-bed stainless reactor (i.d. $10 \mathrm{~mm}$ ). In all the experiments, $2.0 \mathrm{~g}$ of catalyst (40-60 mesh) was placed in the middle of the reactor and activated in situ at $550^{\circ} \mathrm{C}$ for $3 \mathrm{~h}$ under $\mathrm{N}_{2}$ flow of $30 \mathrm{ml} / \mathrm{min}$. Then methanol was pumped to an evaporator with $160^{\circ} \mathrm{C}$ at a rate of $0.042 \mathrm{ml} / \mathrm{min}\left(1 \mathrm{~h}^{-1} \mathrm{WHSV}\right)$ and then was introduced to the reactor by the flowing $\mathrm{N}_{2}$. The MTO reaction was performed at $450^{\circ} \mathrm{C}$.

The reactor exit stream including the ethylene $\left(C_{2}=\right)$, propylene $\left(C_{3}=\right)$, butylenes $\left(C_{4}=\right)$, paraffins $\left(C_{1}-C_{4}\right), C_{5+}$ hydrocarbons, and DME, was separated into gas, liquid hydrocarbons and reaction water fractions using an ice-cooled condenser. The gas product was analyzed by an on-line GC Agilent 7890A with a HP-PLOT capillary column and a flame ionization detector (FID). The oil phase (liquid hydrocarbons) was analyzed by Agilent $7820 \mathrm{~A}$ gas chromatogragh equipped with an OV-101 column and an FID detector. The aqueous phase was analyzed by Agilent 7890A gas chromatogragh equipped with a HP-INNOWAX column and an FID detector. The methanol conversion and selectivities of the products were calculated on the carbon number basis. The methanol conversion $\left(C_{\mathrm{MeOH}}\right)$ was defined as the percentage of $\mathrm{MeOH}$ consumed during the MTO reaction, and the DME was considered as unconverted methanol. The selectivity of each product was calculated as the percentage to the amount (in mole) of $\mathrm{MeOH}$ converted to hydrocarbons. They were calculated according to the following formula, respectively.

$$
C_{\mathrm{MeOH}}=\frac{n(\mathrm{MeOH})_{\text {in }}-n(\mathrm{MeOH})_{\text {out }}-2 n(\mathrm{DME})_{\text {out }}}{n(\mathrm{MeOH})_{\text {in }}} \times 100 \%
$$




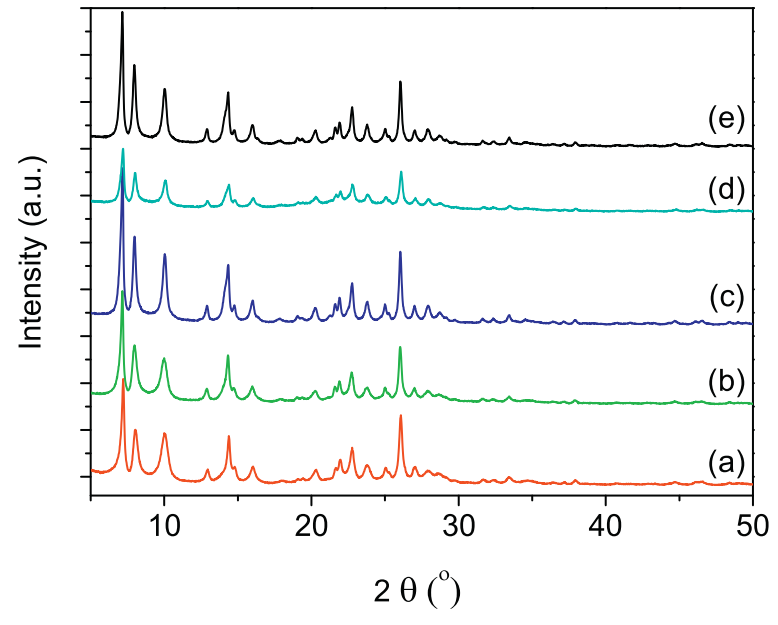

Fig. 1. XRD patterns of (a) H-MCM-22 (10.8), (b) H-MCM-22 (28.3), (c) H-MCM-22 (35.1), (d) H-MCM-22 (49.8) and (e) H-MCM-22 (35.1D) samples.

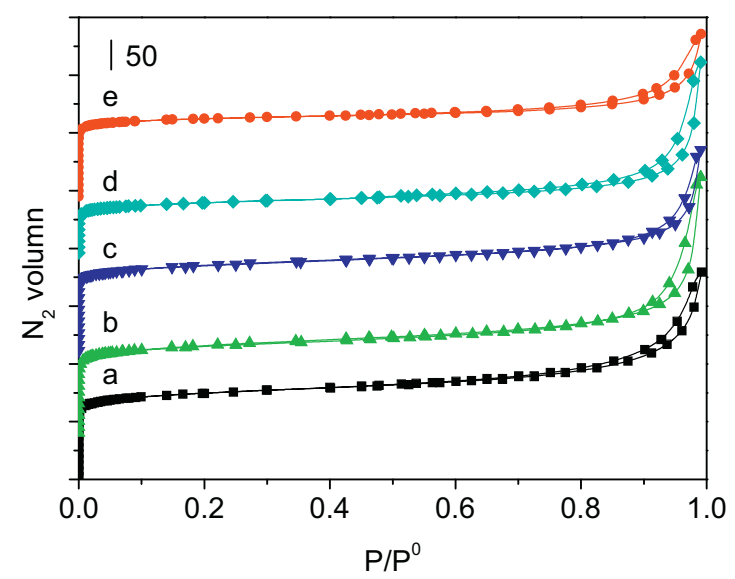

Fig. 2. Nitrogen adsorption-desorption isotherms of (a) H-MCM-22 (10.8), (b) HMCM-22 (28.3), (c) H-MCM-22 (35.1), (d) H-MCM-22 (49.8) and (e) H-MCM-22 (35.1D) samples.

$S_{\mathrm{C}_{x} \mathrm{H}_{y}}=\frac{X \times n\left(\mathrm{C}_{x} \mathrm{H}_{y}\right)_{\text {out }}}{n(\mathrm{MeOH})_{\text {in }}-n(\mathrm{MeOH})_{\text {out }}-2 n(\mathrm{DME})_{\text {out }}} \times 100 \%$

\section{Results and discussion}

\subsection{Catalyst characterization}

Fig. 1 shows the XRD patterns of the parent H-MCM-22 samples with various Si/Al ratios and the dealumination H-MCM-22 (35.1D). It can be seen that all the samples exhibit the typical MWW structure characteristics as reported in Ref. [22]. It can be found that $\mathrm{H}-\mathrm{MCM}-22$ zeolites with $\mathrm{Si} / \mathrm{Al}=10.8,28.3$ and 35.1 display high intensities of the XRD patterns, showing high crystallinity. However, with the $\mathrm{Si} / \mathrm{Al}$ ratio further increasing to 49.8 , the intensities of the XRD pattern exhibit a pronounced reduction compared with other synthesized H-MCM-22 zeolites. The results are in good coincidence with Ref. [8]. As for the H-MCM-22 dealuminated with AHFS, there is almost no effect on the crystalline structure, which can be confirmed by the nitrogen physisorption results (Fig. 2 and Table 1).The acidic properties of H-MCM-22 samples are evaluated by $\mathrm{NH}_{3}$-TPD, as shown in Fig. 3, and the quantitative analysis of $\mathrm{NH}_{3}$-TPD results is summarized in Table 2. For all $\mathrm{H}-$ MCM-22 samples, there are two distinct desorption peaks around

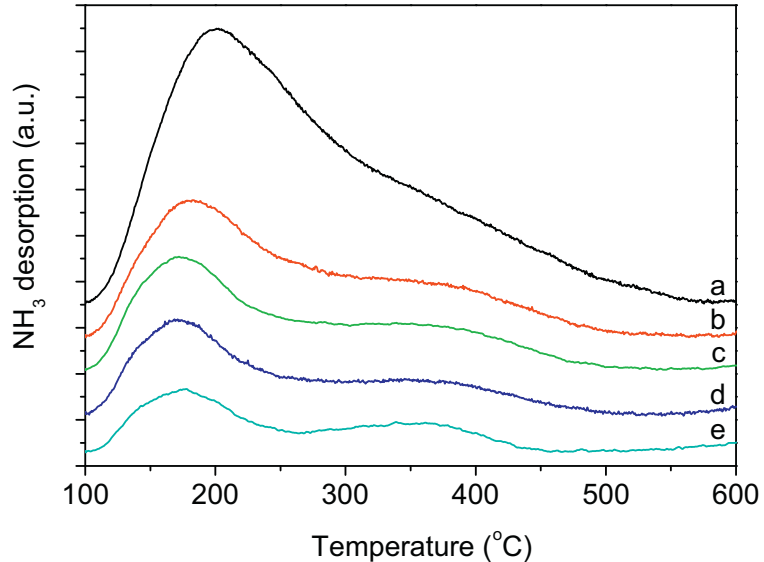

Fig. 3. $\mathrm{NH}_{3}$-TPD spectra of (a) H-MCM-22 (10.8), (b) H-MCM-22 (28.3), (c) H-MCM22 (35.1), (d) H-MCM-22 (49.8) and (e) H-MCM-22 (35.1D) samples.

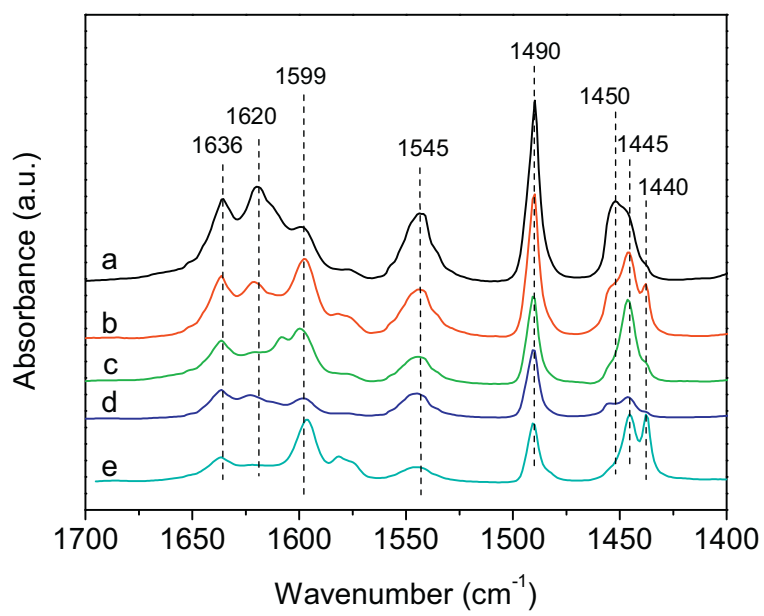

Fig. 4. FTIR spectra of adsorbed pyridine of (a) H-MCM-22 (10.8), (b) H-MCM-22 (28.3), (c) H-MCM-22 (35.1), (d) H-MCM-22 (49.8) and (e) H-MCM-22 (35.1D) samples.

$190^{\circ} \mathrm{C}$ and $360^{\circ} \mathrm{C}$, corresponding to weak acid sites and strong acid sites respectively $[20,23]$. With the $\mathrm{Si} / \mathrm{Al}$ ratios of $10.8-49.8$ were implemented, both of the peak area of weak and strong acid sites decreased, indicating the continuous reduction of weak and strong acid sites on the H-MCM-22 surfaces. As for the dealumination $\mathrm{H}$ MCM-22 (35.1D) sample, the weak and strong acid sites decreased further, while more weak acid sites were removed than strong ones by the AHFS treatment, as shown in Table 2.

Fig. 4 shows the Py-IR spectra of the H-MCM-22 with different $\mathrm{Si} / \mathrm{Al}$ ratios. The bands at 1599 and $1445 \mathrm{~cm}^{-1}$ are associated with hydrogen-bonded pyridine and the band at $1440 \mathrm{~cm}^{-1}$ is ascribed to the physically adsorbed pyridine $[24,25]$. The bands at $1490 \mathrm{~cm}^{-1}$ are characteristic of both Brønsted and Lewis acid sites. The bands at 1450 and $1545 \mathrm{~cm}^{-1}$ are corresponding to Lewis acid sites and Brønsted acid sites respectively. By changing the Si/Al ratio from 10.8 to 49.8 , both of the bands of 1545 and $1450 \mathrm{~cm}^{-1}$ become weak, indicating less Lewis and Brønsted acid sites are generated, as shown in Table 2. Although the AHFS treatment removed considerable amounts of Brønsted and Lewis acid sites, and much more Brønsted than Lewis acid sites were removed.

Fig. 5 depicts the ${ }^{27} \mathrm{Al}$ MAS NMR spectra of all the H-MCM22 samples. Both tetrahedral ( $\mathrm{Al}^{\mathrm{IV}}$, signals around $56 \mathrm{ppm}$ ) and octahedral $\left(\mathrm{Al}^{\mathrm{VI}}\right.$, signal at $\left.0 \mathrm{ppm}\right) \mathrm{Al}$ species are present in all samples and the amount of extra-framework $\mathrm{Al}$ species increased with the $\mathrm{Al}$ content in the sample [8]. Meanwhile, as for the 
Table 2

Acidic properties and the MTO lifetime parameters of different H-MCM-22 catalysts.

\begin{tabular}{|c|c|c|c|c|c|c|c|c|}
\hline \multirow[t]{2}{*}{ Sample } & \multicolumn{4}{|c|}{ Acidity by strength $^{\mathrm{a}}\left(\mathrm{mmol} \mathrm{g}^{-}\right.$Acidity by type ${ }^{\mathrm{b}}\left(\mu \mathrm{mol} \mathrm{g}^{-1}\right)$} & \multirow[b]{2}{*}{$\mathrm{B} / \mathrm{L}$} & \multirow[t]{2}{*}{ Lifetime (h) } & \multirow[t]{2}{*}{ Conversion capacity ${ }^{\mathrm{c}}\left(\mathrm{g} \mathrm{g}^{-1}\right)$} & \multirow[t]{2}{*}{$\operatorname{TOF}^{d}\left(h^{-1}\right)$} \\
\hline & Weak & Strong & Brønsted & Lewis & & & & \\
\hline H-MCM-22 (10.8) & 1.05 & 0.5 & 117.70 & 68.98 & 1.7 & 23 & 23 & 20 \\
\hline H-MCM-22 (28.3) & 0.45 & 0.25 & 82.30 & 29.98 & 2.7 & 31 & 31 & 45 \\
\hline H-MCM-22 (35.1) & 0.38 & 0.17 & 70.44 & 23.29 & 3.0 & 48 & 48 & 56 \\
\hline H-MCM-22 (49.8) & 0.29 & 0.13 & 38.76 & 7.92 & 4.9 & 17 & 17 & 74 \\
\hline H-MCM-22 (35.1D) & 0.17 & 0.11 & 22.30 & 20.76 & 1.1 & 36 & 36 & 111 \\
\hline
\end{tabular}

a Density of the acid sites, assorted according to the acidic strength, determined by $\mathrm{NH}_{3}-\mathrm{TPD}$.

b Density of the acid sites, assorted according to the acidic type, determined by Py-IR.

c The amount ( $\mathrm{g}$ ) of methanol converted per gram of catalyst during the catalyst lifetime.

d TOF was calculated on the basis of total acid sites identified by $\mathrm{NH}_{3}-\mathrm{TPD}$.

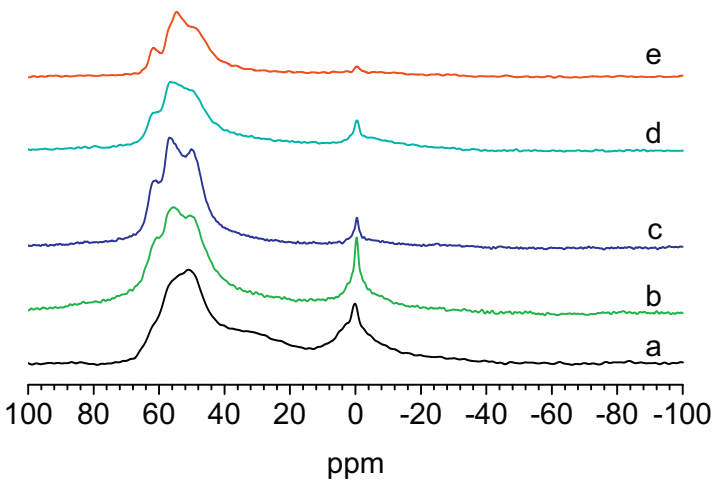

Fig. 5. ${ }^{27} \mathrm{Al}$ MAS NMR spectra of (a) H-MCM-22 (10.8), (b) H-MCM-22 (28.3), (c) H-MCM-22 (35.1), (d) H-MCM-22 (49.8) and (e) HMCM-22 (35.1D) samples.

dealumination $\mathrm{H}-\mathrm{MCM}-22$ (35.1D), the $\mathrm{Al}^{\mathrm{VI}}$ species at 0 ppm almost disappears. This suggests that the dealumination treatment could remove most of the extra-framework Al species. The broad signal around $56 \mathrm{ppm}$ contains at least three components centered at 50.5, 56.0 and $61.5 \mathrm{ppm}$, which are attributed to the $\mathrm{Al}$ species located at crystallographically different $\mathrm{T}$ sites $[8,26]$. Obviously, the relative intensities of the three components change with the $\mathrm{Si} / \mathrm{Al}$ ratio increasing, this indicates that the Al distribution in the framework depends on its content in the samples [8]. Interestingly, as for the dealumination H-MCM-22 (35.1D), the relative intensity of the Al species at $50.5 \mathrm{ppm}$ reduced, this suggests that the AHFS treatment also can remove some framework $\mathrm{Al}$ species. Anyway, the $\mathrm{Al}^{\mathrm{F}} / \mathrm{Al}^{\mathrm{EF}}$ ratio (Table 1) of dealuminated sample was increased significantly, compared to the parent one. This illustrates that much more extraframework than framework Al species were removed by the AHFS treatment.

\subsection{Catalytic performance}

The catalytic results of methanol conversion to olefins over $\mathrm{H}-\mathrm{MCM}-22$ with different $\mathrm{Si} / \mathrm{Al}$ ratios and the dealumination $\mathrm{H}$ MCM-22 (35.1D) are shown in Fig. 6, and the data were collected with time on stream at $450^{\circ} \mathrm{C}$ and $1 \mathrm{~h}^{-1}$. Fig. 6 A shows the methanol conversion vs. time on stream for the parent and the dealuminated H-MCM-22 samples during the MTO reaction. All the H-MCM-22 samples, regardless of their Si/Al ratio, exhibit initial methanol conversions of nearly $100 \%$. The catalyst stability is estimated by using the reaction time for complete methanol conversion at a certain WHSV according to Refs. [11,27-33], and the catalyst lifetime is different from one another. As the $\mathrm{Si} / \mathrm{Al}$ ratio increased from 10.8 to 35.1 , the catalytic lifetime increased from 23 to $48 \mathrm{~h}$. However, with the $\mathrm{Si} / \mathrm{Al}$ ratio further increasing to 49.8 , the catalytic lifetime dramatically decreased to $17 \mathrm{~h}$, which may be due to the presence of lower amounts of acid sites, especially for the amount of the Lewis acid sites in the sample (Table 2). However, as for the dealumination H-MCM-22 (35.1D) sample, the lifetime was about $36 \mathrm{~h}$, this may be ascribed to the increase of Lewis acid sites, as shown in Table 1.

Another parameter related to the catalyst stability to deactivation is the conversion capacity that is the amount of methanol converted per gram of catalyst during the catalyst lifetime [18]. Obviously, the H-MCM-22 (35.1) has highest conversion capacity. Meanwhile the combination of higher conversion capacity and the least acid sites results in the highest turnover frequency (TOF) over the H-MCM-22 (35.1D) catalyst, as listed in Table 2.

As for the product selectivity over H-MCM-22 samples under investigation, the products mainly contain light olefins (ethylene, propylene and butylene) and alkanes and some liquid products (water and oil). The light olefins selectivities are shown in Fig. 6. The ethylene selectivity (Fig. 6B) decreased with increasing Si/Al ratio as a result of the decrease of the acid sites amount. While the initial propylene and butylene selectivities increased during the lifetime (all the samples have the similar methanol conversion of $100 \%$ ) with the Si/Al ratio increasing from 10.8 to 49.8 , and then the H-MCM-22 (49.8) decreased quickly with the shortest lifetime, as shown in Fig. 6C and D. As for the dealumination H-MCM-22 (35.1D) sample, the propylene and butylene selectivities were enhanced further with decreasing the selectivity of ethylene to some extent. Therefore, the $\mathrm{P} / \mathrm{E}\left(\mathrm{C}_{3}=/ \mathrm{C}_{2}=\right)$ ratio increased with the Si/Al ratio increasing with and without dealumination with AHFS, as shown in Fig. 6E. Also Fig. 6F gives the $\mathrm{CH}_{4}$ selectivity, as suggested that it can be an indication for the deposition of large amount of coke, because $\mathrm{CH}_{4}$ was considered to be generated by methylation of the coke with methanol [9]. Interestingly, compared with the parent H-MCM-22 sample, the dealumination H-MCM-22 (35.1D) sample has more slow increase in the methane selectivity. This suggested that the dealumination treatment can inhibit the coke deposition to some extent.

Concerning the acidic properties of H-MCM-22 samples, it seems that the catalytic stability is related to the amount of acid sites, some extent decrease of the acid sites is beneficial to prolong the catalytic lifetime, however, when the amount of Lewis acid decreases too much, the catalytic stability seems to be destroyed, as shown in Table 2. Meanwhile, with the $\mathrm{Si} / \mathrm{Al}$ ratio increasing from 10.8 to 49.8 , the propylene and butylene selectivities increased although the amounts of Brønsted acid sites decreased. As for the dealumination H-MCM-22 (35.1D), the amounts of Brønsted acid sites decreased further, with the amounts of the Lewis acid sites increased, the propylene and butylene selectivities increased further with higher catalytic stability. Hence, it seems that the light 

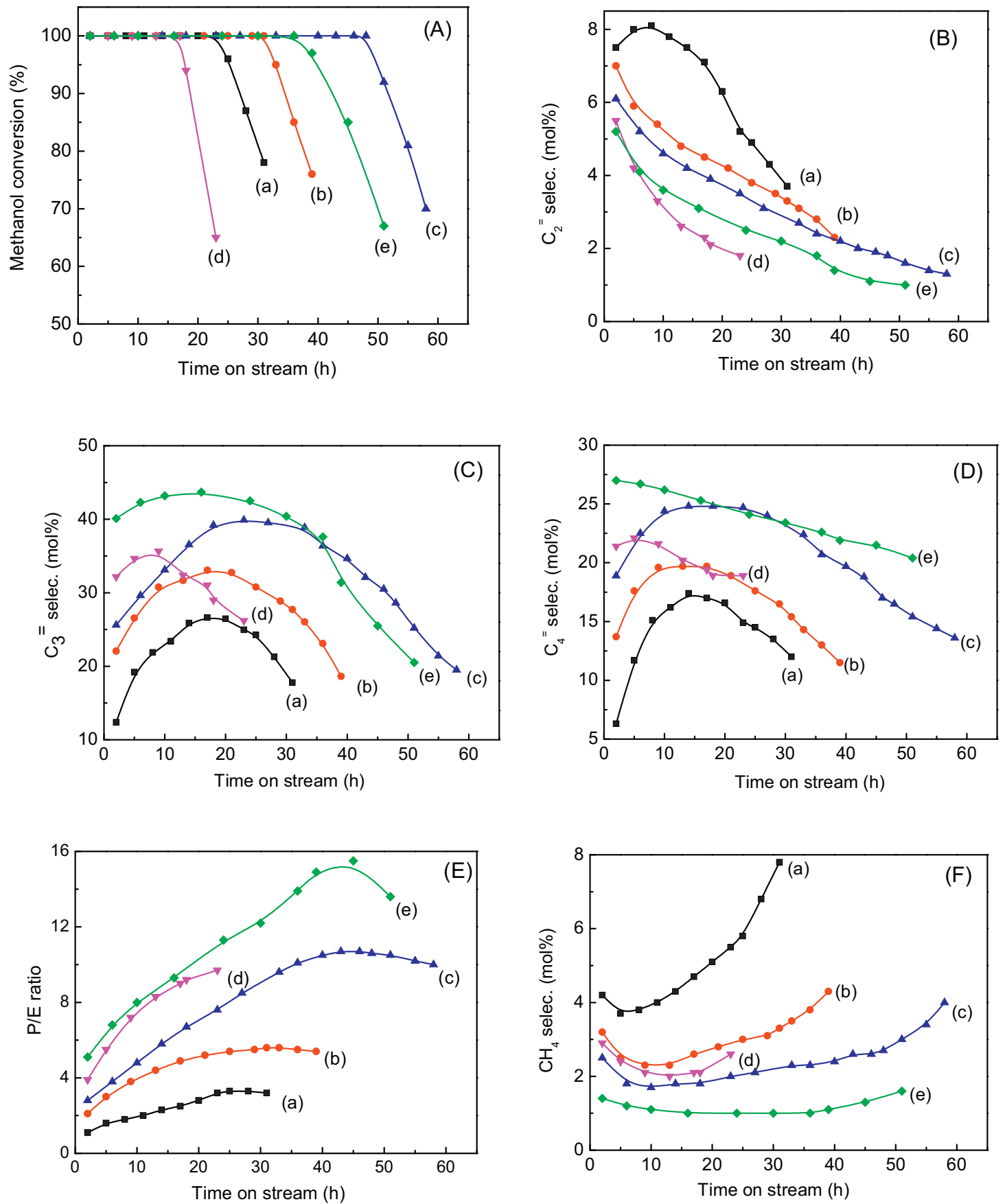

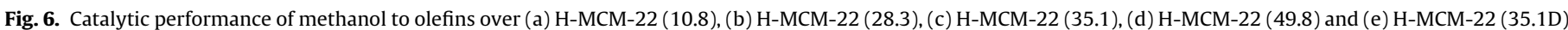
samples.

olefin selectivity is related to the amounts of the Brønsted acid sites, and the stability is related to the amounts of Lewis acid sites.

\section{Conclusions}

A series of $\mathrm{H}-\mathrm{MCM}-22$ samples with $\mathrm{Si} / \mathrm{Al}$ ratios from 10.8 to 49.8 were hydrothermally synthesized, and also the H-MCM-22 (35.1) was dealuminated by AHFS. The amount of $\mathrm{Al}^{\mathrm{VI}}$ species decreased with increasing $\mathrm{Si} / \mathrm{Al}$ ratio in the sample, and the $\mathrm{Al}^{\mathrm{VI}}$ species in the dealuminated sample almost disappears, showing that much more extra-framework Al species were removed by the AHFS treatment. The MTO catalytic properties of H-MCM-22 are highly dependent on its acidic properties. An increase in the Si/Al ratio leads to an increase of the propylene and butylene selectivities but a decrease in ethylene selectivity. It seems that the catalytic stability is related to the amount of acid sites especially the Lewis acid sites, too much or too less Lewis acid does not benefit to improve the catalytic stability. The H-MCM-22 with Si/Al ratio of 35.1 exhibits much higher catalytic stability than the other samples because of its suitable acid site amount and distribution. And the light olefin selectivity seems to be related to the amounts of Brønsted acid sites, the less Brønsted acid sites and the higher light olefin selectivity. The dealumination H-MCM-22 (35.1D) has the fewest Brønsted acid sites, it has the highest light olefin selectivity. 


\section{Acknowledgments}

The authors are grateful for financial support by the Chinese Academy of Sciences Research Program (No. XDA07070301), the National Science Foundation of China (No. 21403264), the Qingdao Institute of Bioenergy and Bioprocess Technology Director Innovation Foundation for Young Scientists (Grant No. CASKLB201502) and the Applied Basic Research Programs of Qingdao (Grant No. 14-2-4-53-jch).

\section{References}

[1] U. Olsbye, S. Svelle, K.P. Lillerud, Z.H. Wei, Y.Y. Chen, J.F. Li, J.G. Wang, W.B. Fan, Chem. Soc. Rev. 44 (2015) 7155-7176.

[2] W. Dai, X. Wang, G. Wu, N. Guan, M. Hunger, L. Li, ACS Catal. 1 (2011) 292-299.

[3] C.D. Chang, Catal. Rev. Sci. Eng. 25 (1983) 1-118.

[4] U. Olsbye, S. Svelle, M. Bjorgen, P. Beato, T.V.W. Janssens, F. Joensen, S. Bordiga, K.P. Lillerud, Angew. Chem. Int. Ed. 51 (2012) 5810-5831.

[5] M.A. Deimund, J.E. Schmidt, M.E. Davis, Top. Catal. 58 (2015) 416-423.

[6] J.Q. Chen, A. Bozzano, B. Glover, T. Fuglerud, S. Kvisle, Catal. Today 106 (2005) 103-107.

[7] G. Yang, Y. Wei, S. Xu, J. Chen, J. Li, Z. Li, J. Yu, R. Xu, J. Phys. Chem. C 117 (2013) $8214-8222$.

[8] P. Wang, L. Huang, J. Li, M. Dong, J. Wang, T. Tatsumi, W. Fan, RSC Adv. 5 (2015) 28794-28802.

[9] P. Tian, Y. Wei, M. Ye, Z. Liu, ACS Catal. 5 (2015) 1922-1938.

[10] S. Hu, Y. Gong, Q. Xu, X. Liu, Q. Zhang, L. Zhang, T. Dou, Catal. Commun. 28 (2012) 95-99.

[11] C. Mei, P. Wen, Z. Liu, H. Liu, Y. Wang, W. Yang, Z. Xie, W. Hua, Z. Gao, J. Catal, 258 (2008) 243-249.

[12] S. Park, Y. Watanabe, Y. Nishita, T. Fukuoka, S. Inagaki, Y. Kubota, J. Catal. 319 (2014) 265-273.
[13] W. Xia, A. Takahashi, I. Nakamura, H. Shimada, T. Fujitani, J. Mol. Catal. A: Chem. 328 (2010) 114-118.

[14] M.E. Leonowicz, J.A. Lawton, S.L. Lawton, M.K. Rubin, Science 264 (1994) $1910-1913$

[15] S. Lawton, M.E. Leonowicz, R. Partridge, P. Chu, M.K. Rubin, Microporous Mesoporous Mater. 23 (1998) 109-117.

[16] H.-K. Min, M.B. Park, S.B. Hong, J. Catal. 271 (2010) 186-194.

[17] X. Wang, W. Dai, G. Wu, L. Li, N. Guan, M. Hunger, Microporous Mesoporous Mater. 151 (2012) 99-106.

[18] A. Lacarriere, F. Luck, D. Swierczynski, F. Fajula, V. Hulea, Appl. Catal. A Gen. 402 (2011) 208-217.

[19] A. Corma, C. Corell, J. Perezpariente, Zeolites 15 (1995) 2-8.

[20] X. Niu, J. Gao, Q. Miao, M. Dong, G. Wang, W. Fan, Z. Qin, J. Wang, Microporous Mesoporous Mater. 197 (2014) 252-261.

[21] F.F. Madeira, K. Ben Tayeb, L. Pinard, H. Vezin, S. Maury, N. Cadran, Appl. Catal A Gen. 443 (2012) 171-180.

[22] A. Corma, V. Martinez-Soria, E. Schnoeveld, J. Catal. 192 (2000) 163-173.

[23] X. Li, D. Han, H. Wang, G. Liu, B. Wang, Z. Li, J. Wu, Fuel 144 (2015) 9-14.

[24] L. Li, J. Ding, J.G. Jiang, Z. Zhu, P. Wu, Chin. J. Catal. 36 (2015) 820-828.

[25] P. Li, G. Liu, H. Wu, Y. Liu, J.g. Jiang, P. Wu, J. Phys. Chem. C 115 (2011) 3663-3670

[26] E. Lippmaa, A. Samoson, M. Magi, J. Am. Chem. Soc. 108 (1986) 1730-1735.

[27] Z. Hu, H. Zhang, L. Wang, H. Zhang, Y. Zhang, H. Xu, W. Shen, Y. Tang, Catal. Sci. Technol. 4 (2014) 2891-2895.

[28] M. Milina, S. Mitchell, P. Crivelli, D. Cooke, J. Perez-Ramirez, Nat. Commun. 3922 (2014), http://dx.doi.org/10.1038/ncomms4922.

[29] M. Yoshioka, T. Yokoi, T. Tatsumi, ACS Catal. 5 (2015) 4268-4275

[30] L. Wu, V. Degirmenci, P.C.M.M. Magusin, N.J.H.G.M. Lousberg, E.J.M. Hensen, J. Catal. 298 (2013) 27-40.

[31] Q. Sun, N. Wang, D. Xi, M. Yang, J.H. Yu, Chem. Commun. 50 (2014) 6502-6505.

[32] M. Choi, K. Na, J. Kim, Y. Sakamoto, O. Terasaki, R. Ryoo, Nature 461 (2009) 246-249.

[33] R. Chal, C. Gerardin, M. Bulut, S. van Donk, ChemCatChem 3 (2011) 67-81. 